\title{
ESTRUCTURAS NARRATIVAS \\ DEL CUENTO LA MUJER, DE JUAN BOSCH
}

\author{
RAFAEL JULIAN \\ DAMASO BELLO
}

\section{1.. INTRODUCCION}

1.1 La semiótica se define como una transcodificación. Toma la forma de un metalenguaje respecto al universo de sentido que se propone como objeto de análisis. Pero esto no es todo. Para evitar convertirse en una simple paráfrasis, el quehacer semiótico tiene, como uno de sus postulados operacionales, el llamado principio de la pertinencia: esto significa que los objetos estudiados no son enfocados más que bajo un aspecto bien determinado común a todos ellos. La semiótica postula, pues, que el estudio de la significación no puede hacerse sino mediante aproximaciones diversas, es decir, según niveles definidos por el conjunto de rasgos distintivos que son comunes a todos los objetos estudiados.

El principio de pertinencia aparecerá necesariamente como una reducción respecto al material sometido a análisis. La práctica semió tica no estudia los objetos dados (por ejemplo: textos, relatos orales, tiras cómicas, obras cinematográficas, planos arquitectónicos, obras musicales, etc.) más que bajo un ángulo particular: su análisis no pretende reproducirlos sino dar cuenta del objeto que ella construye a partir o através de ellos. La semiótica no se ocupa de un solo nivel de análisis, permitiendo así la posibilidad de otras aproximaciones a los mismos objetos, aproximaciones con las cuales ella mantiene una relación de complementaridad.

1.2. Uno de los objetos propios de la semiótica es la narratividad. Para Greimas 
ésta "consiste en una o varias transformaciones cuyos resultados son junciones, es decir, conjunciones o disyunciones de los sujetos con relación a los objetos". 1

Una vez determinado el nivel de análisis, la semiótica narrativa se ocupa de revelar su organización fundamental. La primera operación consiste en articular uno por uno los diferentes niveles de aproximación, buscando hacer el inventario de las unidades que los constituyen. Aquí se sitúa la etapa de definición de los constituyentes (según la terminología lingüística) por las relaciones que éstos tienen entre sí (estudio morfológico), tanto en el plano sintagmático como en el paradigmático, y se determinan las reglas de sus posibles combinaciones (estudio sintagmático). En una segunda etapa, el análisis buscará integrar los diferentes niveles en un conjunto coherente de naturaleza jerárquica.

1.3. Los modelos elaborados por la semiótica son modelos cuya existencia puede preceder a toda manifestación, lingüística o no, permitiendo conocer universos de significación diversos sin importar sus modos o vehículos de expresión.

Tomemos, como ejemplo, un cuento oral. Tenemos aquí una manifestación textual (de tipo lingü ístico) que se define como la reunión de una expresión (de for. ma lingüistica: en una lengua natural) y de un contenido (parcialmente autónomo, puesto que puede ser retomado en otra lengua natural, o bajo forma de imágenes, gestos, filme, tira cómica, mímica, etc.). Este plano de manifestación no puede constituir un nivel satisfactorio de análisis. Según Greimas: "Desde Hjeimslev sabemos que nada bueno puede hacerse en lingüística mientras no se sobrepase este nivel, mientras no nos dediquemos a explorar, después de haber separado los planos del significante y del significado, las unidades a la vez más pequeñas y más profundas de los dos planos considerados individualmente".

1.4. Hasta ahora, la lingü ística se ha ocupado del estudio del significante. Pocos estudios han sido consagrados al significado. Lo propio del hacer semiótico será, por el contrario, abandonar parcialmente y en un primer momento el plano de la forma lingü ística para ocuparse del significado.

El análisis del contenido tomará como modelo lo practicado en el estudio del plano de la expresión. Se postula el paralelismo entre el plano de la expresión y el plano del contenido (tesis sausseriana), y con esto se da una idea del modo de existencia y articulación de la significación. Además, se considera el plano de la expresión como constitu ído por rasgos diferenciales, condición de la presencia del sentido articulado $y$, en consecuencia, instrumentos de apreciación de la ade-

1. A. J. Greimas. "Un problème de sémiotique narrative: les objets de valeur". Langages, (31): 20, 1973.

2. A.). Greimas. "Les actants, les acteurs et les figures", Sémiotique narrative et textuelle. Paris, 1973. p. 169. 
cuación de los modelos utilizados para la descripción del plano semántico (conforme a la regla, derivada del principio del paralelismo, según la cual a todo cambio en el plano de la expresión corresponde uno en el plano del contenido).

Para Greimas, en materia de análisis narrativo, la forma de la expresión y la forma del contenido pueden ser homólogas, ya que se derivan de una sola forma linguística, pero no son isomorfas: los planos de la expresión y del contenido se articulan de dos maneras diferentes.

1.5. Otra distinción fundamental es la establecida por Hjelmslev, para quien los dos planos, el de la expresión y el del contenido se articulan internamente según la oposición forma versus substancia. Un enunciado lingüístico, por ejemplo, contiene en el plano de la expresión, una forma constituída por el sistema fonológico (fonemas), y una substancial (cadena fónica). En el plano del contenido, presenta, igualmente; una forma constituída por una gramática, con sus componentes morfológico y sintáctico, y una substancia constituída por una masa semántica.

Retomando el ejemplo del cuento oral, podemos decir que éste presenta, en el plano del contenido, dos elementos diferentes articulados entre sí: a) un componente gramatical que permite la composición y el enlace de los enunciados narrativos: es el caso de las estructuras formales que determinan el género "cuento" con sus mecanismos narrativos particulares; y b) un componente semántico, de orden conceptual y/o figurativo, que corresponde al revestimiento del ordenamiento formal. Una misma estructura narrativa del tipo carencia/búsqueda/adquisición, puede encontrarse en materiales semánticos diferentes, según se trate de un cuento popular, de una novela policíaca, o autobiográfica, etc.

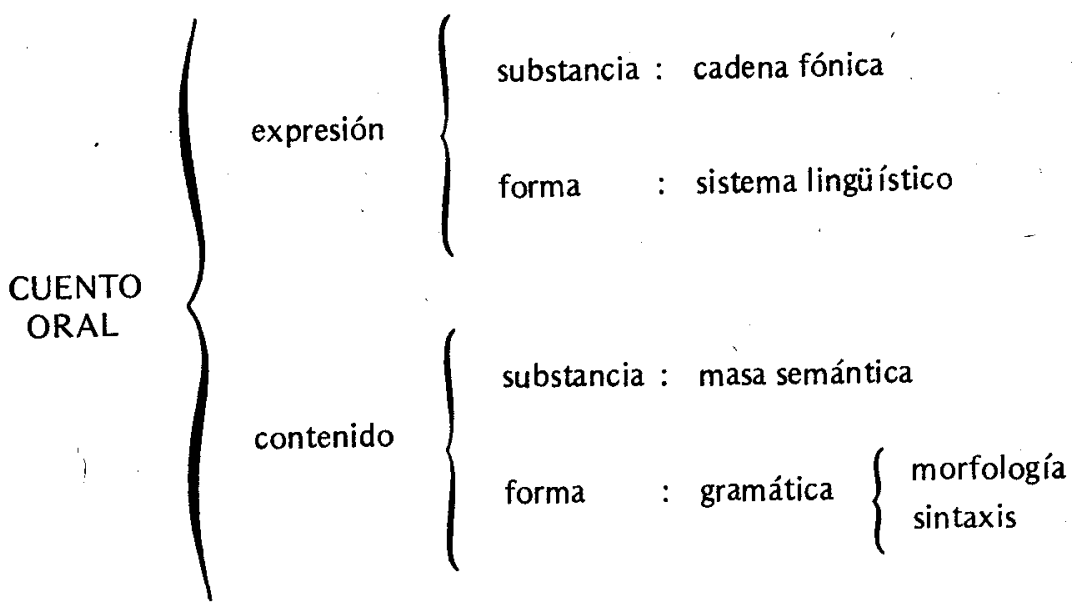


Para Greimas, "La oposición entre forma y substancia se encuentra, pues, situada por completo en el interior del análisis del contenido; no es la oposición del significante (forma) y del significado (contenido), como una larga tradición del Siglo XIX quería hacérnoslo entender. La forma significa tanto como la substancia, $y$ es sorprendente que esta formulación no haya podido lograr la aceptación que merece".

El análisis semiótico recaerá sobre dos planos: el plano de la substancia del contenido y el plano de la forma del contenido. El primero no puede ser aprehendido sino a través del segundo, el cual consiste en una gramática, integrada por una morfología y una sintaxis.

Nivel superficial

Nivel profundo
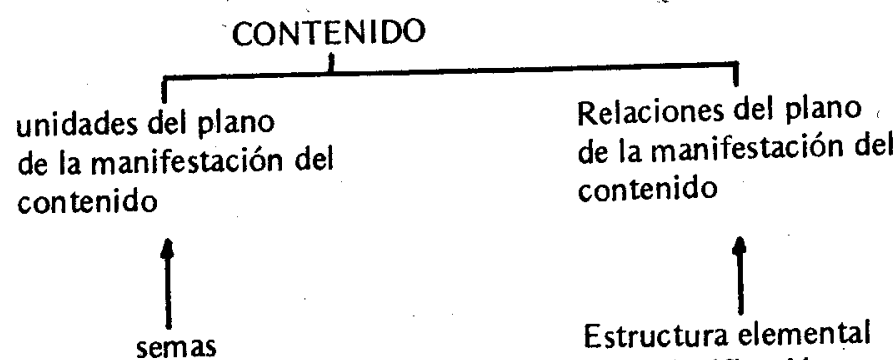

(universo inmanente)

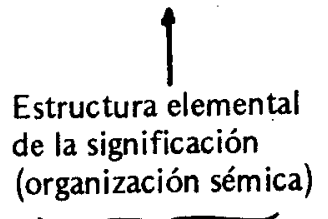

Sintaxis

Dentro del plano del contenido, nuestro trabajo ha privilegiado el nivel superficial (planos de las sememas y de la estructura actancial). En él se encuentran recogidos, aunque no se expliquen las operaciones de análisis que permitieron su aprehensión, los contenidos del universo inmanente y de la estructura elemental de significación del cuento La Mujer. Habernos detenido en el análisis del ordenamiento sémico, hubiera exigido disponer de mucho más tiempo.

\section{ANALISIS DEL CONTENIDO.}

Nosotros postulamos que el cuento La Mujer relata la reinserción del sujeto en el mundo natural o mundo de la economía de autosubsistencia. La estructura sintáctica de esta reinserción toma la forma de este enunciado:

$$
\text { SUOEA-S }
$$

3. A.J. Greimas. Sémantique Structurale. Paris, Ed. Larousse, 1966. p. 26. 
En él S representa al sujeto y OEA-S representa al objeto, los cuales pasan de un estado de disyunción a otro de conjunción. El sujeto, que rompió el modelo social, tendrá como programa restablecer la rẹlación contractual con el mundo de la autosubsistencia.

Este mundo natural o mundo de la economía de autosubsistencia se opone al mundo cultural o mundo de la economía mercantil.

\subsection{MORFOLOGIA.}

2.2. Los polos semánticos son fácilmente identificables. Podemos dar una lista de sememas (lexemas y sintagmas) pertenecientes a cada uno de estos polos:

\section{POLOS SEMANTICOS}

LEXEMAS

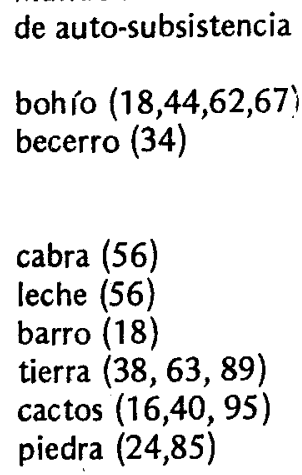

No la quemaba el sol (36)

Planicie dorada (39)

Piso de tierra (63)

La llevó hasta el bohro (67)

Prefirió no tener unas monedas (59)

No vendió la leche (56)

La tierra del piso absorbía aquella sangre -Chepe veía la luz brillar en ella. (89)

$Y$ cactos, embutidos en el acero (96)
Mundo cultural o economía mercantil

carretera $(1,4,5,9,10,17,22,24,29$, $33,39,64,65,71,93,96)$ auto (34)

agua $(66,21,38,66)$

camisa $(68)$

monedas (59)

acero $(3,4,9,17,39,71,96)$

picos (7)

palos (7)

\section{Sintagmas}

Pronto iba la carretera a quemar el cuerpecito (29)

Pesado acero transparente (39)

piel gris, lomo de la gran momia (65)

La arrastró hasta la carretera (64)

A que la criaturita sufriera hambre (59-60)

Tener unas monedas más (59)

Aquel polvo murió también y se posó en la piel gris (13)

La desenterraron hombres con picos $y$ palas $(6,7)$ 
La cabra produce vida (leche) (56)

Sólo se destaca el techo

Queso, seco... las canas dieron, esas techumbres por las que nunca rueda agua. (19-22)

El cause de un río; las fauces secas de la tierra que tuvo agua mil años antes de hoy. $(37,38)$

Estaba allí tirada sin que la brisa le moviera los harapos (25)

Se resquebraba la planicie dorada (39)
Como el auto produce muerte (34) (estropea becerro) Quico tenía agua para dos días más de camino, pero casi toda la gastó en rociar la frente de la mujer. $(66,67)$

pensó romper la camisa listada para limpiarla de sangre (68)

Bajo el pesado acero transparente $(39,40)$

3. SINTAXIS.

3.1. El modelo actancial (abstracto) se presenta de la manera siguiente:

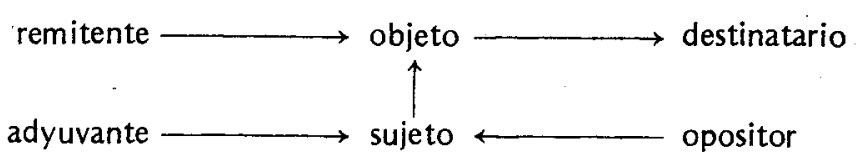

En el cuento La Mujer, este modelo se manifiesta como sigue:

\section{Sujeto \\ Objeto}

Remitente

Destinatario

Opositor

Adyuvante
Chepe.

reinserción del sujeto en la economía de autosubsistencia.

Sistema de autosubsistencia.

Campesino (de autosubsistencia).

Quico.

La Mujer.

Como veíamos antes, tenemos dos formas de enunciados de estado:
1) enunciado disyuntivo:
SUOEA-S
2) enunciado conjuntivo:
SNOEA-S

El primero se mantiene hasta el final del cuento, donde se produce su transformación, la cual establece la conjunción entre el sujeto y el objeto. El va- 
lor virtual, que como valor indeterminado se encontraba invertido en el objeto disjunto del sujeto, aparecerá ahora como valor realizado.

Esta transformación se opera sin que el sujeto sufra modalización, y la misma es posible por la acción del adyuvante (La Mujer). Recordemos, sin embargo, que la acción del adyuvante no es más que una exteriorización de la naturaleza profunda del héroe (el sujeto).

No queremos dejar de señalar el carácter maravilloso de la acción del adyuvante, que asegura la conversión del contenido invertido en contenido enuncia- ' do: "sintió que le nacía una fuerza brutal-" (85-88).

$$
\frac{\text { Antes }}{\text { Después }} \sim \frac{\text { contenido invertido }}{\text { contenido enunciado }}
$$

Este carácter maravilloso está justificado por la importancia de la acción del adyuvante en la estructura narrativa general del cuento. Es esta acción la que definirá no sóló a Chepe como sujeto, sino también a Quico como opositor, al campesino como destinatario y la reinserción del sujeto en la economía de autosubsistencia como objeto:

\section{MODELO ACTANCIAL}

\section{- (antropomorfo)}

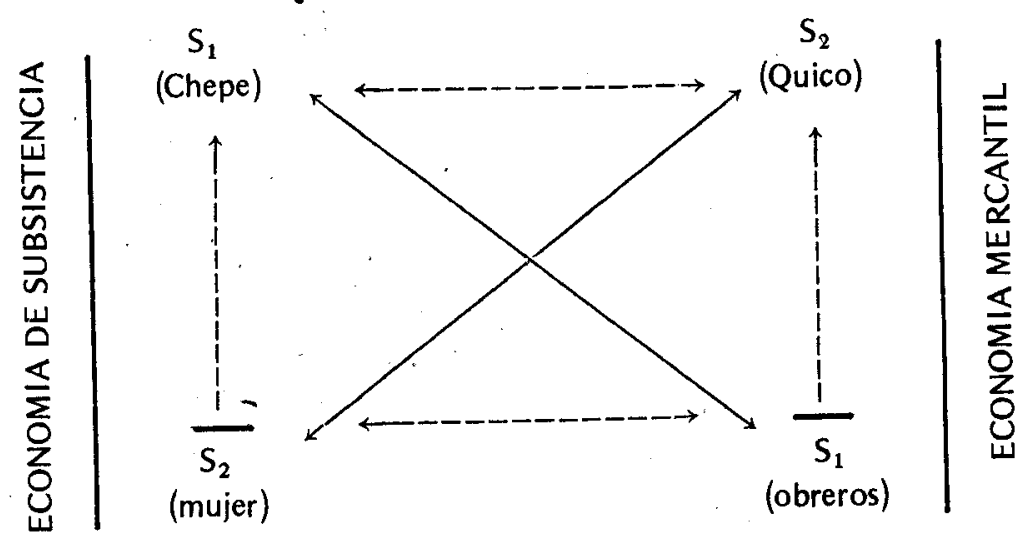

El signo $\longrightarrow$ significa (NO) 
Un aspecto esencial para la comprensión del modelo actancial del cuento La Mujer es el que se refiere al espacio.

Mientras se permanece en el espacio del bohío, se asiste a una especie de contradicción artificial entre Chepe y La Mujer, manifestada bajo la forma de celos:

“- iHija de mala madre! iHija de mala madre!

iTe voy a matar como a una perra, desvergonsá! $(46,47)$

- iPero si nadie pasó, Chepe; nadie pasó! -Quería ella explicar $(48,49)$

Esta parte del relato plantea uno de los problemas más difíciles de resolver desde el punto de vista semiótico: la indefinición actancial. Así pues, no podemos hablar, hasta el momento de Chepe como sujeto ni de la mujer como adyuvante. El contenido invertido, con su estructura actancial y su nivel figurativo se mantiene casi hasta el final del relato. La historia visible que nos es contada es una historia de celos, de oposición entre dos individuos (marido y mujer), a propósito de un objeto de valor (leche). Esa apariencia no será destruída sino al final, cuando el desplazamiento de la mujer hacia la carretera traerá como resultado el surgimiento del oponente y el desplazamiento de éste de su espacio (carretera) a un espacio extraño (bohío).

\section{MODELO DEL COMPORTAMIENTO CONYUGAL}

Verosimilitud

SER

(amor)

PARECER

(infidelidad)
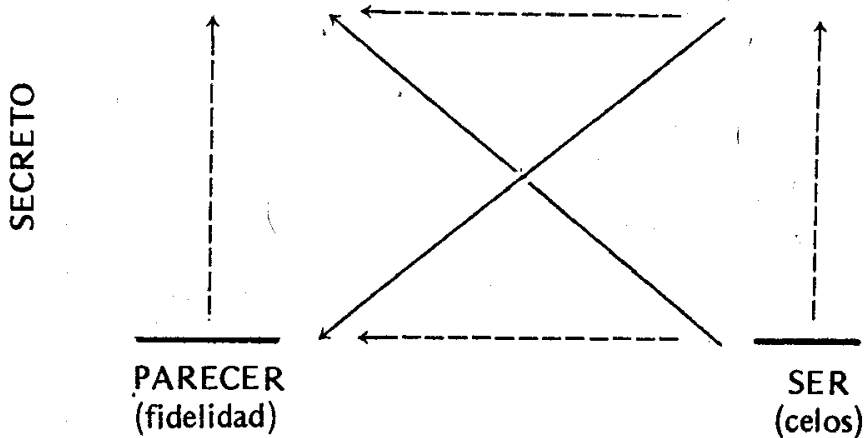
La conjunción de la mujer con el espacio carretera opera como la mediación que hace posible el encuentro del sujeto y el antisujeto (Chepe y Quico). La mujer, elemento doméstico por excelencia, pierde la conjunción con su espacio normal en beneficio de la realización del enfrentamiento entre el sujeto y el antisujeto.

Este enfrentamiento tiene lugar en el espacio que hemos llamado doméstico (espacio de la vida y de la riqueza).

MODELO ESPACIAL

$E_{1}$

$$
E_{2}
$$

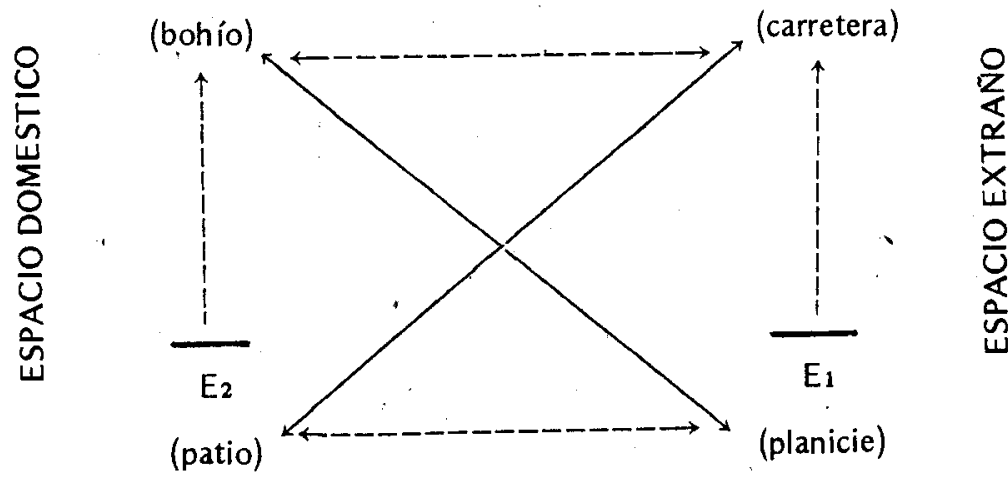

El adyuvante (mujer), no sólo "provoca" la entrada al espacio doméstico del "extraño", sino que es agente de la derrota de éste. La mujer permanecerá, pues, a lo largo del cuento como el elemento que relaciona a Chepe, aún sea virtualmente, con el mundo de la subsistencia, que él había abandonado, y es a través de este adyuvante que se expresará la competencia del suje to (Chepe) al final del cuento, asegurando así la transformación del contenido invertido. Esta unidad narrativa (la performance o actuación que presupone la competencia) está integrada por tres enunciados narrativos:

$$
\begin{array}{ll}
\mathrm{EN} 1=\mathrm{F}: & \text { Confrontación }(\mathrm{S} 1 \longleftrightarrow \mathrm{S} 2) \\
\mathrm{EN} 2=\mathrm{F}: & \text { Dominación } \quad(\mathrm{S} 1 \longrightarrow \mathrm{S} 2) \\
\mathrm{EN} 3=\mathrm{F}: & \text { Atribucion } \quad(\mathrm{S} 1 \longleftrightarrow \mathrm{O})
\end{array}
$$

El contenido enunciado, hecho posible por la derrota del antisujeto (Qui- 
co = sistema mercantil), puede ser semióticamente apreheridido con ayuda de este esquema sintáctico:

\section{MODELO DEL UNIVERSO SEMANTICO}

Prescripción

(Sistema de antosubsistencia)

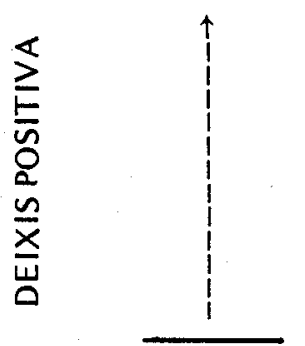

Prohibición (beberse la leche)
Prohibición

(Sistema mercantil) .
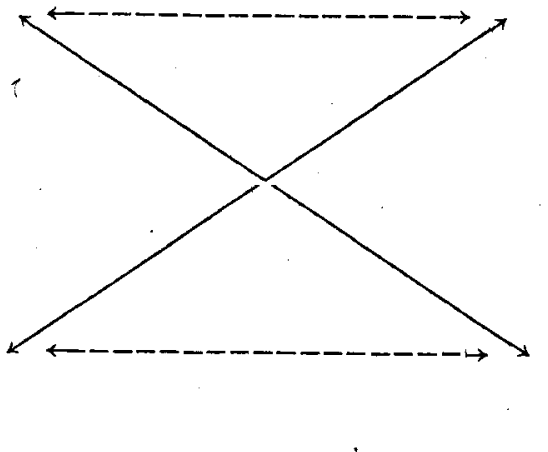

Prescripción (vender la leche)

Así pues, este cuento es la historia de la confrontación entre el sistema mercantil y el sistema de autosubsistencia, y de la derrota del primero a manos de este último. La otra historia, la de los celos (contradicción artificial -Para la caracterización de este problema- Véaser Luis Althuser: Notas para un teatro materialista, "La revolución teórica de Marx, Siglo XXI editores) no funciona sino sobre el plano modal de la veridicción (es decir, de las instancias que sostienen la "verdad" del cuento), permitiéndole al enunciante un rejuego de contenido antropologistas. Pero quien se quede en esta historia antropologista, elaborada sobre la base de un modelo de relaciones interindividuales no conocerá la historia profunda. Esta historia antropologista es sólo una cortina de humo, hecha posible por una dialéctica que se ejerce en el vacío, está resumida en la fórmula folklórica universal que señala "no te metas en pleito de marido y mujer" (su equivalente francés: II faut pas mettre tron doigt entre l'arbre et l'écorce-Citamos de memoria), en la cual la solidaridad (la unidad actancial) no es, a fin de cuentas, sino el efecto de una relación de contigüidad.

Este cuento es la historia de la confrontación entre dos sistemas económico-sociales y es la historia de un enunciante que, consciente o inconscientemente, le dijo no a la historia folklórica.

Este triunfo de la economía de autosubsistencia es una batalla ganada en la 
guerra (perdida para la economía de subsistencia) de la historia. La inevitabilidad del capitalismo (a largo alcance él ganará la guerra) no se ve como algo negativo. Lo inaceptable es la forma en que éste aparece, importado, en Santo Domingo. A la riqueza de oropel (carro, camisa listada, dinero, carretera, buenas maneras, agua transportada) del capitalismo extranjero, este cuento opone la riqueza mesurada de la autosubsistencia (cabra, leche, becerro, yagua, cana, bohío, espontaneidad), pues si esta riqueza mesurada se pierde no hay ninguna posibilidad de alcanzar aquella de oropel. O mejor, esta última no es posible sin la negación de la primera: la riqueza capitalista se levanta sobre la miseria del campesino proletarizado. Es a los inicios de un proceso de proletarización que se realiza mediante la introducción de relaciones monetarizadas (salariales y de comercio: ${ }^{`}$ ¡El salario no es más que lo pagado en la compra de fuerza de trabajo!), que asistimos los lectores de la historia profunda contada en este relato. Es la resistencia opuesta por el sistema de subsistencia al sistema mercantil invasor, el núcleo semántico de este relato.

MODELO SOCIO-ECONOMICO (RIQUEZA VERSUS POBREZA) VEROSIMILITUD

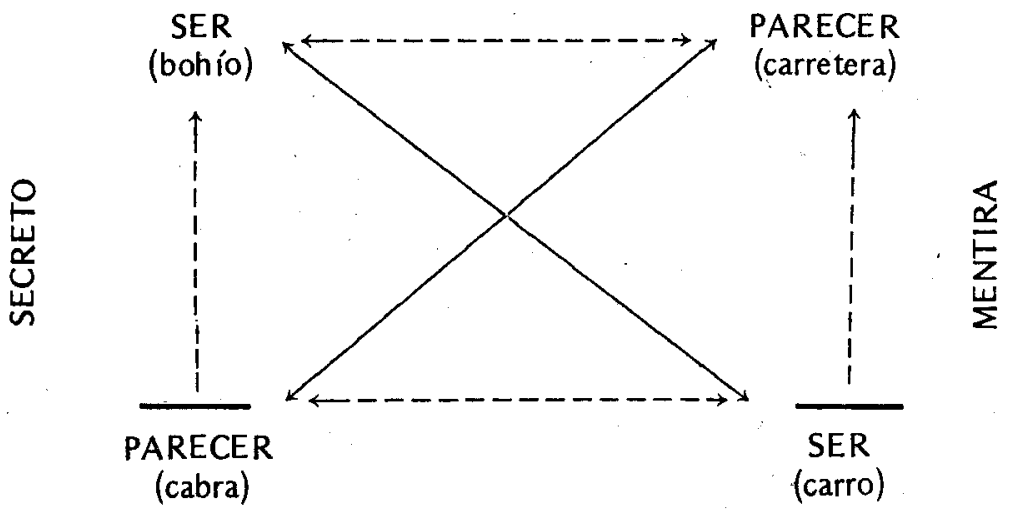


ANEXO:

TERMINOLOGIA SEMIOTICA

\section{ACTANTE}

1. Actante lingüistico: término de la frase susceptible de jugar el rol de sujeto, de objeto o de destinatario (L. Tesniére).

2. Actante semántico: unidad del relato; clase de actores (A.J. Greimas).

\section{CUADRO SEMIOTICO O MODELO CONSTITUCIONAL}

Estructura de cuatro términos recíprocamente interdefinidos. Esta estructura elemental está concebida como el desarrollo lógico de una categoría sémica binaria, del tipo blanco versus negro, cuyos términos están unidos, entre si, por una relación de contrariedad. Cada uno de los términos es, a la vez, susceptible de proyectar un nuevo término que sería su contradictorio. Los términos contradictorios pueden, a su vez, contrastar una relación de presuposición respecto al término contrario opuesto (A.J. Greimas).

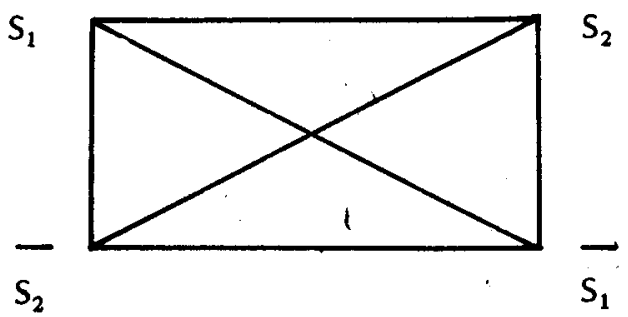

\section{PERFORMANCE O ACTUACION (Teoría de' la)}

En gramática generativa, la performance o actuación es la manifestación de la competencia de los sujetos hablantes en sus múltiples actos de habla (Diccionario de lingüística, Larousse).

\section{PRESUPOSICION}

Los enunciados de una lengua natural, así como el discurso, al mismo tiem- 
po que pretenden dar ciertas informaciones nuevas para, así, instruir al oyente (yo sé que Pablo es arrogante), vehiculan otras que son presentadas como la simple vocación de conocimientos anteriores, admitidos definitivamente, e indiscutibles. Estas últimas son las que llamamos presuposiciones (Pablo es arrogante).

La conservación de los presupuestos es una de las leyes que definen la estructura del discurso (O. Ducrot).

\section{NARRATIVIDAD}

Consiste en uno o varias transformaciones cuyos resultados son junciones, es decir, sea conjunciones, sea disyunciones de los sujetos con relación a los objetos. (A.). Greimas).

En términos más figurativos, "la narratividad, considerada como la irrupción de lo discontinuo en la permanencia discursiva de una vida, de una historia, de un individuo, de una cultura, la desarticula en estados discretos entre los cuales ella sitúa transformaciones: esto permite describirla, en un primer momento, bajo la forma de enunciados de hacer que afectan enunciados de estado. Estos últimos presentándose como los garantes de la existencia semiótica de los sujetos que están en junción con los objetos investidos de valor (A.J. Greimas).

\section{ENUNCIADOS NARRATIVOS}

Formas sintácticas elementales engendradas a partir de la combinación de los actantes (sujeto, objeto, remitente, etc.) y las funciones (hacer transformador). Ejemplos de enunciados narrativos: confrontación, dominación, atribución (A.J. Greimas).

\section{UNIDAD NARRATIVA}

Es la resultante de una serie de enunciados unidos por una relación de implicación, del tipo:

$$
\text { EN3つEN2 つ EN1 }
$$

Ejemplo: la performancia o actuación presenta tres enunciados narrativos (confrontación, dominación, atribución) unidos por una relación de implicación. 


\section{SINTAGMA}

Cualquier grupo de palabras unidas por una relación sintáctica.

\section{SINTAXIS}

1. Parte de la gramática que describe las reglas mediante las cuales se combinan en frases las unidades significativas (Diccionario de lingüística, Larousse).

2. Conjunto de reglas que explicitan el funcionamiento del discurso.

\section{SINTAGMACION}

Operación que permite la formación de unidades semánticas complejas. Como consecuencia de su coaptación, "las palabras adquieren valores que ellas no poseían por sí mismas y que son, incluso, contradictorios de aquellos que poseían anteriormente. Vemos unirse conceptos lógicamente opuestos y que incluso se refuerzan al juntarse. Esto es tan común que ya no tenemos consciencia de ello: así, la unión entre haber y perder en yo he perdido, entre ir y venir en él va a venir [...]. El proceso de la auxiliación en el verbo ilustra bien esta transformación que las condiciones de empleo " pueden producir en el sentido mismo de las palabras llamadas a conocer una sintagmación estrecha" ( $E$. Benveniste).

\section{SEMA}

Unidad semántica de base. Elemento mínimo de significación. No aparece más que en relación con otro elemento distinto: no tiene sino una función diferencial $y$, por lo tanto, sólo puede ser aprehendido en el interior de un conjunto orgánico, dentro del marco de una estructura. Por ejemplo, veamos los dos lexemas

$$
\text { "hijo" e "hija" }
$$

Puede decirse que poseen un sema común sobre el eje del /engendramiento/ (en su relación de filiación respecto a uno a los dos padres), y un sema diferente sobre el eje de la sexualidad:/masculinidad/ en un caso, /feminidad/ en el otro (A.J. Greimas). 


\section{MODALIDADES}

Subclase de la clase de las funciones. Son tipificadas por el carácter hiperotáxico (jerárquico) de la relación que los une al predicado. Así, en las secuencias:
A Juan le gusta tocar la guitarra, La tierra parece redonda.

le gusta y parece son modalidades que, lógicamente anteriores a los predicados, constituyen el marco de su modificación.

\section{BIBLIOGRAFIA}

1. Coquet, J.C. "Sémantique du discours et analyse du contenu". Connexions, (11): 93-119, 1974. Epi Editeurs, S.A., París.

2. Courtès, J. Lévi-Strauss et les contraintes de la pensée mythique. París, Mame, 1973.

3.- - Introduction a la sémantique narrative et discursive. París, Hachette, 1976.

4. Greimas, A.J. "Les actants, les acteurs et les figures". Dans: Sémiotique narrative et textuelle, recueil collectif. Paris, Larousse, 1973. Páginas 161-176.

5.--- Du sens. Paris, Du Sevil, 1970. De esta obra hay traducción al español.

6.--- Maupassant, la sémantique du texte. París, Du Sevil, 1976.

7._-_- Sémantique structurale. Paris, Larousse, 1966. De esta obra hay traducción al español.

8. - - Semiotique et sciences sociales. Paris, Du Sevil, 1976.

9._-_-. Un problème de Sémiotique narrative: les objets de Valeur, in Langages (31), Paris, Didier -Larousse, 1973.

10. Julián, Rafael. Contexte socio-cultural et littérature orale á Santo Domingo: essai d'analysse ethno-sémiotique d'un conte dominicain d'origine africaine. Paris, Universidad René Descartes, Paris V, 1978.

Tesis de Maestría. 